\title{
FUNDO DE FINANCIAMENTO ESTUDANTIL (FIES): VICISSITUDES E DESAFIOS
}

Vicente de Paula Almeida Júnior ${ }^{1}$

Pedro Antônio Estrella Pedrosa

\section{INTRODUÇÃO}

Este artigo resume as principais alteraçóes ocorridas no Fundo de Financiamento Estudantil (Fies) a partir da Lei no 13.530/2017 e apresenta alguns desafios e oportunidades de melhorias para o programa a partir da nova lei.

O texto está organizado em três seçôes. A primeira situa o Fies em conjunto com o Programa Universidade para Todos (Prouni), as Bolsas de Certificação de Entidades Beneficentes de Assistência Social (CEBAS) e o Programa de Estímulo à Reestruturação e ao Fortalecimento das Instituiçóes de Ensino Superior (Proies), todos empreendidos pelo Ministério da Educação (MEC) para favorecer o acesso à educação superior no país, especificamente ao ensino superior privado, responsável por 75,3\% do total das matrículas ofertadas nesse nível de ensino. A segunda seção apresenta as linhas gerais do novo financiamento estudantil. Por sua vez, a terceira esboça os principais desafios e oportunidades de melhorias para o aperfeiçoamento da política educacional em curso.

\section{FIES NO CONTEXTO DOS PROGRAMAS DE ACESSO À EDUCAÇÃO SUPERIOR NO BRASIL}

Dados do Censo da Educação Superior 2017, divulgados pelo Instituto Nacional de Estudos e Pesquisas Educacionais Anísio Teixeira (Inep), mostram que o percentual de matrículas na rede privada de ensino superior com algum tipo de financiamento e/ou bolsa no Brasil alcançou 46,3\% do total de matrículas do setor (gráfico 1).

\section{GRÁFICO 1}

Matrículas na rede privada com algum tipo de financiamento/bolsa - Brasil (2009-2017)

(Em \%)

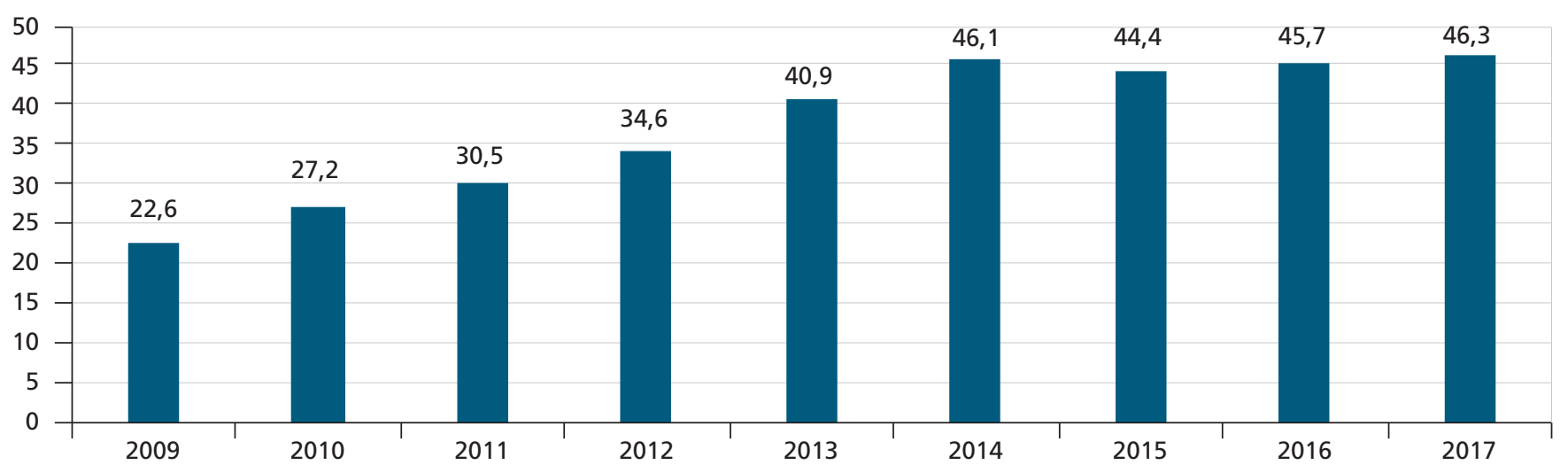

Fonte: Inep/MEC.

Elaboração dos autores.

1. Diretor de Políticas e Programas de Educação Superior do Ministério da Educação (DPPES/SESu/MEC). Pós-doutor em educação superior pela Universidade de São Paulo (USP). Doutor em educação pela Universidade Estadual de Campinas (Unicamp). E-mail: <vicente.junior@mec.gov.br>.

2. Diretor na Diretoria de Gestão de Fundos e Benefícios (Digef); Fundo Nacional de Desenvolvimento da Educação (FNDE) do MEC. Mestre em economia e previdência pela Universidade de Brasília (UnB).E-mail: <pedro.pedrosa@fnde.gov.br>. 
Entre os programas citados, o Prouni e o Fies se destacam na realidade educacional brasileira por abrirem as possiblidades de acesso ao ensino superior privado. O gráfico 2 mostra a evoluçáo de ambos ao longo do tempo em relação às matrículas da rede privada.

GRÁFICO 2

Matrícula na rede privada por tipo de financiamento/bolsa - Brasil (2009-2017)

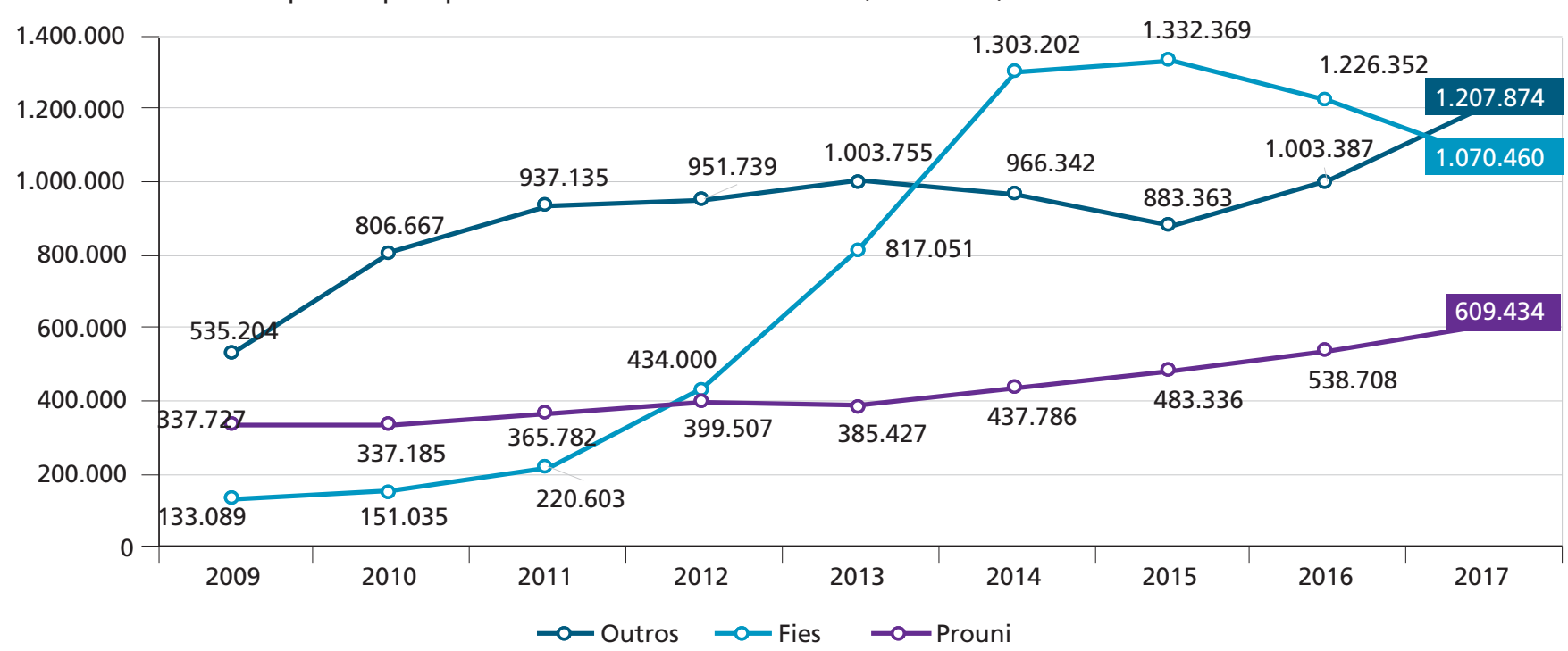

Fonte: Inep/MEC.

O Prouni, instituído pela Lei no 11.096/2005, é um programa de concessão de bolsas de estudo integrais e parciais de cinquenta por cento $(50 \%)$ para estudantes brasileiros de cursos de graduação em instituiçóes privadas de ensino superior com avaliação positiva no Sistema Nacional de Avaliação da Educaçáo Superior (Sinaes). Como contrapartida à adesão ao programa, as instituiçôes ficam isentas de alguns impostos e contribuiçóes ${ }^{3}$ no período de vigência do termo de adesão. O programa não se configura como uma ação orçamentária, isto é, não tem impacto sobre o orçamento consignado anualmente para o MEC.

O Fies, por sua vez, tem impacto considerável sobre o orçamento da União, como já visto neste Radar. Além da perspectiva orçamentária, o programa tem enorme relevância acadêmica. Conforme os dados do Censo da Educação Superior 2017, o Fies representa 37,1\% do total das matrículas da rede privada, enquanto o Prouni 21,1\% e outros programas fomentados pelo MEC, 41,8\% das matrículas.

As modificaçôes trazidas pela Lei n⿳⺈ $13.530 / 2017$ e pelo Comitê Gestor do Fundo de Financiamento Estudantil (CG-Fies) remodelaram o programa, ampliando modalidades, possibilitando juro real zero a estudante com renda de até 3 salários mínimos e escala de financiamento variada conforme a renda familiar do candidato, além de implementar novo modelo de gestão e governança.

\section{NOVO FUNDO DE FINANCIAMENTO ESTUDANTIL (FIES): LINHAS GERAIS}

Até o primeiro semestre de 2015, para obter o financiamento estudantil por meio do programa, bastava o estudante acessar o sistema do MEC em qualquer período do ano. Mediante o preenchimento de um cadastro no sistema, informava os seus dados pessoais e financeiros e indicava a instituição e curso para o qual pretendia

3. Isenções de Impostos e contribuições no Prouni: i) imposto de renda das pessoas jurídicas; ii) contribuição social sobre o lucro líquido; iii) contribuição social para financiamento da seguridade social; e iv) contribuição para o Programa de Integração Social. 
contratar o empréstimo. Após conclusão do cadastro, o estudante se dirigia à instituição de ensino escolhida e, com as informaçóes já validadas, comparecia ao agente financeiro (banco) para celebrar o contrato.

A partir do segundo semestre de 2015, adotou-se novos parâmetros para ingresso de estudantes interessados em obter o financiamento, passando a ser exigido nota mínima de 450 (quatrocentos e cinquenta) pontos na média do Exame Nacional do Ensino Médio (Enem) e nota diferente de zero na redação. Além disso, ocorreram outras mudanças no período: disponibilização de vagas conforme previsão em Lei Orçamentária Anual (LOA); concessão do financiamento a estudantes com renda familiar mensal bruta per capita de até dois e meio salários mínimos; prioridade na oferta de financiamento em cursos com conceitos positivos no Sistema Nacional de Avaliação da Educação Superior (Sinaes); prioridade na oferta de financiamento em cursos nas áreas de formação de professores (licenciatura, pedagogia e normal superior), saúde e engenharias.

A partir do segundo semestre de 2016, as diretrizes e as regras para a sustentabilidade do programa, notadamente sobre os processos de adesão das entidades mantenedoras e processo seletivo de estudantes, foram aprofundados e redesenhados sob novas bases, permitindo mais modalidades de financiamento, adoção de critérios mais objetivos e auditáveis e clareza nas responsabilidades dos atores envolvidos (Órgãos de governo, agentes financeiros, instituiçôes de ensino e estudantes). Portanto, não se restringem ao aspecto fiscal, a fim de garantir a sua eficiência e controle, mas também em relação à própria política educacional e governança do programa, melhorando as informações e condiçôes de acesso para os estudantes e instituições participantes.

Nesse quadro e dado que o programa envolve vários setores de governo e da sociedade, o CG-Fies disciplina as regras e diretrizes do programa, estabelecendo o orçamento e o quantitativo de vagas para determinado exercício fiscal. As vagas são distribuídas conforme um algoritmo cujas variáveis consideram a demanda por ensino superior apurada por mesorregião, áreas prioritárias (formação de professores, saúde, engenharias e ciências da computação) e conceito de qualidade do curso.

O processo de adesão das entidades mantenedoras inicia-se a partir de calendário previamente divulgado, momento em que as instituiçóes ofertam um certo quantitativo de vagas para o programa. Em cada instituição, limita-se as vagas financiáveis às autorizadas por processos de regulação e avaliação coordenados pelo MEC, e pelo conceito de qualidade do curso participante.

No novo processo de seleção, os estudantes inscrevem-se e concorrem a uma das vagas a partir da nota obtida no Enem. De acordo com as suas preferências ou escolhas (por estado, município, curso, conceito de curso, área e subárea de conhecimento) os estudantes definem no processo de inscrição o curso e a instituição de seu desejo, obtendo no próprio sistema informaçóes claras sobre os valores globais do curso, comparativamente com outros cursos e instituiçôes, mensalidades, parcelas, juros, qualidade do curso pretendido e número de vagas disponíveis. Os processos de adesão das instituiçóes e de seleção dos estudantes envolvem duas modalidades no Novo Fies.

A primeira modalidade é direcionada a estudantes com renda familiar bruta de até três salários mínimos per capita, e oferece melhores condiçóes de financiamento e uma série de outras melhorias na gestão e transparência do programa para os estudantes. Uma inovação trazida é a previsão de taxa de juros reais zero, enquanto a taxa de juros nominal fixada à época da publicação da norma era de 6,5\%.

Além disso, respeitando a capacidade de pagamento do estudante, o prazo e a forma de pagamento das prestaçóes do financiamento passou a ser mediante a vinculação do valor da prestaçáo à renda efetiva do financiado. $\mathrm{O}$ valor da prestação foi calculado de maneira proporcional ao salário bruto do estudante financiado, mediante retenção diretamente na fonte pagadora e recolhimento direto ao Fies. Assim, o período de amortizaçáo passou a depender da renda do estudante - medida que constituiu importante mecanismo de mitigação da inadimplência. Aliada a essas medidas, o agente financeiro, de acordo com as diretrizes do MEC e do CG-Fies, definiu possibilidade de pactuar medidas de estímulo à liquidação ou reescalonamento das dívidas vencidas, visando a assegurar o retorno dos capitais emprestados. 
A segunda modalidade do Novo FIES, denominada de P-FIES, é constituída parcialmente por recursos públicos (via fundos constitucionais regionais e Banco Nacional de Desenvolvimento Econômico e Social BNDES) e operacionalizada por instituiçôes financeiras autorizadas a funcionar pelo Banco Central do Brasil, sejam elas públicas ou privadas, que passam a assumir integralmente o risco de crédito das operaçóes e o custo de captação (taxa de longo prazo - TLP) e pode atender, na forma da regulamentação, estudantes com renda bruta familiar mensal de até cinco salários mínimos per capita, contando com garantia exclusivamente privada.

No contexto das alteraçóes voltadas à sustentabilidade do Fies, está a eliminação da fase de carência do financiamento, período compreendido entre a fase na qual o estudante está frequentando a graduação e a fase de amortização, quando o estudante começa a pagar as prestaçôes do empréstimo. Como o estudante já efetua durante o curso o pagamento às instituições de ensino da parcela da mensalidade náo financiada pelo programa, o objetivo da medida é que mantenha a disciplina de pagamentos imediatamente após a conclusão do curso. Adicionalmente, a medida contribui para que os recursos emprestados comecem a retornar ao Fundo mais cedo, pois o prazo de carência existente antes era de dezoito meses.

Durante o período do curso, como forma de estimular o efetivo acompanhamento da evoluçáo dos preços praticados pelas instituiçóes de ensino, os estudantes pagarão diretamente ao agente financeiro o valor correspondente à parcela das mensalidades não financiadas (coparticipação). Em substituição ao pagamento trimestral de juros de até R \$ 150,00 praticado anteriormente, o estudante irá efetuar o pagamento do valor equivalente às despesas operacionais do agente financeiro e de seguro prestamista para cobertura da totalidade do contrato.

O novo Fundo Garantidor do Fies (FG-Fies) teve integralização inicial da União e participação das entidades mantenedoras das instituiçóes de ensino. Inicialmente, a participação destas foi fixada em $13 \%$ do valor dos encargos educacionais financiados, participação esta que variará no futuro de acordo com o patamar de inadimplência dos egressos de cada instituição de ensino. O Fundo tem por objetivo a complementariedade de renda dentro do prazo de amortização e a garantia do risco de crédito dos financiamentos. Os estudantes com renda familiar mensal bruta per capita de até um salário-mínimo e meio têm a cobertura exclusiva do FG-Fies e os estudantes com renda superior precisarão indicar fiador. $\mathrm{O}$ aumento da participação no risco de crédito por parte das instituiçóes de ensino potencializou os efeitos da política ao facilitar o acesso dos estudantes de menor renda aos cursos de nível superior, contribuindo para a formação de mão de obra qualificada, cada vez mais necessária para obtenção de um crescimento sustentável de médio e longo prazos, visto que haverá a certeza de retorno dos capitais investidos pelo Fies, pois eventuais perdas serão assumidas exclusivamente pelo FG-Fies.

\section{DESAFIOS E OPORTUNIDADES DE MELHORIA}

Passado o esforço inicial da implementação das novas mudanças do programa, torna-se necessário começar a pensar nas possíveis melhorias que podem ser feitas para aperfeiçoar a política pública. Não se deve perder de vista o objetivo de proporcionar o acesso dos estudantes ao crédito estudantil e de se manter náo-pagamento em níveis sustentáveis.

O primeiro estudo técnico que deve ser feito é sobre o impacto fiscal de se retirar a parcela de pagamento mínimo dos estudantes recém-formados que ainda não possuem uma renda formal. Este ajuste aproximaria o novo Fies das boas práticas internacionais, pautadas em empréstimos com amortizaçóes contingentes à renda futura (ECRs).

Outro ponto que deve ser alvo de melhorias é qualidade da carteira dos financiamentos da modalidade antiga. Atualmente, os índices de inadimplência já passaram dos $50 \%$ para os estudantes em fase de amortização. A grande preocupação é que quando a maior parte da carteira alcançar a fase de pagamento, o prejuízo para a União pode passar dos R \$ 30 bilhóes. Nesse sentido, os agentes financeiros do programa devem melhorar as formas 
de cobrança, utilizando-se das novas tecnologias disponíveis no mercado (SMS, e-mails e centrais telefônicas), para aproximar dos alunos inadimplentes, principalmente nos primeiros dias de atraso.

Necessita-se também desenvolver novos planos de renegociaçáo de dívidas, com opçóes de reparcelamento e refinanciamento, nos moldes de modelos bancários de crédito de varejo. Atualmente, a única maneira que o aluno inadimplente possui de renegociar a sua dívida é com o pagamento integral do seu saldo, à vista. O objetivo de uma campanha de renegociação é conseguir trazer os alunos que náo possuíam renda no momento do início da fase de pagamento, mas que agora possuem renda formal.

Por fim, deve-se buscar o fortalecimento das modalidades do P-FIES, com atuação de bancos comerciais. Essa fonte alternativa de recursos é essencial para expandir a base de financiamento educacional no país. A atuação de bancos regionais, que conhecem as particularidades do mercado de trabalho da regiáo, é essencial para ampliar a base de estudantes nas regióes mais carentes. Vale reforçar que nessa modalidade o governo federal não possui o risco na operação.

Destaque-se que o FIES, reformulado sob novas bases, juntamente com o Prouni, o Sistema de Seleção Unificada (Sisu) e a Lei de Cotas, tem importante papel na indução de políticas para o acesso e a permanência em cursos superiores de contingente populacional que historicamente esteve excluído desse nível educacional. 
